
Production
ENGINEERING
2016, Vol. 12, No. 3, pp 5-8
ARCHIVES
ISSN 2353-5156
(print version)
ISSN 2353-7779
(online version)

Article history: Received: 01.09.2016 Accepted: 11.09.2016 Online: 30.09.2016

Available online on: http://www.qpij.pl

Exist since $4^{\text {rd }}$ quarter 2013

\title{
Improvement of working environment conditions in the logistic terminal
}

\author{
Magdalena Dobosz ${ }^{1}$ \\ ${ }^{1}$ Podkarpackie Teaching Service Centre, ul. Rymanowska 15a, 35-083 Rzeszow, Poland, 696429796, mdobosz@pcud.edu.pl.
}

\begin{abstract}
The authors of this article analyse and propose improvement of safety and health at work in the transshipment terminal of a logistics company. The character of the place means that workers are exposed to constant overload of their musculoskeletal system, which is defined in the process of transporting the cargo of considerable weight. After analysing changes in the conditions of safety and health at work on selected positions were proposed. Qualitative research using the observation method, as well as the quantitative approach after changes in working conditions show the change of attitudes of employees to their work and higher performance. After a year of the proposed changes, a decision was made to introduce them also into external companies and for employees working in the cargo transshipment terminal.
\end{abstract}

Keywords - improvement of working conditions, work quality and productivity, safety,

\section{Introduction}

Building and shaping the culture of safety and health at work is an ongoing process as the achievement of a real change is extremely difficult and gradual. Quality and efficiency of safety changes must be made in each business, and all employees need to be involved in this process. Health and safety management systems are an intricate part of the overall company management system. The implemented system is a collection of effectively interacting elements that shape the policy of health and safety in the organization.

Regardless of the profession, the employee is always exposed to hazards that can cause a partial or long-term injury. All the factors of work environment shape occupational hazard that must be estimated for each position. The ordinance of the Minister of Labour and Social Policy of 26 September 1997 (Journal of
Law of 2003, No. 169, item 1650 as amended) $\$ 2$ point 7 defines what the occupational risk is. It is the probability of harmful occurrences associated with work which may result in losses of different type, especially connected with adverse health effects due to occupational hazard in a given working environment or resulting from the way work is performed.

Each element of work environment should be estimated and corrected in case of anomalies. The expert team analysed the working environment at the transshipment terminal of a logistics company. The analysis of working conditions was the reason to take action to improve the quality and productivity.

\section{Analysis of health and safety condi- tions at the transshipment terminal}

The scope of activities on the transshipment terminal of the logistics company focused around: 
- unloading,

- loading,

- reloading of goods.

Within the area of transshipment terminal there are different types of shipment which are difficult to categorise in terms of size and weight. The variability of the load each time shapes other working conditions, and other risks to which workers are exposed. Regulation of the Minister of Labour and Social Policy on health and safety in manual handling asserts the following:

$\$ 211$. Gross vehicle weight of cargo shipped on the carriage on the flat hard surface, plus the mass of the buggy cannot exceed:

1) $350 \mathrm{~kg}$ - on a 2-wheel buggy,

2) $450 \mathrm{~kg}$ - on a 3- or 4-wheel buggy.

2. When moving the load on the carriage on the slopes greater than $5 \%$, the weight of the load, including the weight of the buggy cannot exceed:

1) $250 \mathrm{~kg}$ - on a 2-wheel buggy,

2) $350 \mathrm{~kg}$ - in a 3- or 4-wheel buggy (Journal of Law of 2003, No. 169, item. 1650 as amended).

Variability of weight and size of transported goods by a pallet truck exposes an to overload of the musculoskeletal system. That is why diversity of cargo is important as weight and volume influence directly the tension of individual muscle groups.

The cited regulation prohibits unloading, loading and reloading of goods which exceed $450 \mathrm{~kg}$ by casual workers ( in the plant 4 - wheel buggies are used). However, it is difficult to imagine the functioning of a transhipment terminal where each commodity over $450 \mathrm{~kg}$ would be transported by a truck. The analysis resulted in a change of working conditions at the terminal. The team of experts on health and safety at the transhipment terminal indicated that the vast majority of goods weighing more than $450 \mathrm{~kg}$ were carried by employees with the use of HPTs.

Training and lectures by health and safety inspectors outlined a new policy and showed the existing and future threats in the workplace after making changes in the work environment. Showing good practices and positive habits is the key to achieve the goals. Training prepared employees for a change, and they were also familiar with the new procedures associated with the use of electric pallet trucks.

The use of electric pallet trucks gave rise to a change in the culture of safety and health at work. The scope of changes significantly transforms the work environment at the transhipment terminal of the logistics company. The actions taken by auditors led to the following situation:
- the worker was exposed to transporting goods over $450 \mathrm{~kg}$ on the hand pallet truck,

- the productivity of employees improved (goods over $450 \mathrm{~kg}$ are transported more quickly, without the involvement of another employee or a forklift),

- the quality of work improved (using electric pallet trucks meant that the employees themselves could move goods more than $450 \mathrm{~kg}$, which meant more room for other goods.

A team of experts on health and safety conducted quantitative research among employees of the terminal a month after the changes were implemented. The survey covered all the staff members directly affected by the change. $75 \%$ of the employees assessed the change that took place at the transshipment terminal of the logistics company positively. The hand pallet trucks are still used, but the introduction of their electric counterparts provided and opportunity for an employee to individually assess the way of cargo transportation. For more details see: Dobosz M., Saja P., Pacana A., Woźny A., Improvement of health and safety conditions at selected workplaces - on the example of transshipment terminal of a logistics compa$n y$, [in:] Production Management and Engineering Sciences, London 2016, s. 55-59.

\section{Implementation of the electric pallet trucks at the terminal}

The implementation of the changes concerning the improvement of working conditions and their adaptation to the applicable regulations of safety and health at work forced employers to purchase electric pallet forklifts. It is worth noticing that the actions of the employer and the inspector are not limited solely to the purchase of electric pallet trucks. Their use is associated with changes in the terminal area. These activities centred around:

- an organization of the room for accumulators, where the trucks will be loaded,

- examination of the explosive atmosphere and installation of the hydrogen detector which is isolated during the change of electric pallet trucks,

- separation of space for trucks storage,

- training of personnel.

The actions taken by management and a safety inspector helped to reduce the potential failure in meeting the standards of goods carriage by terminal staff and drivers. 
Figure 1 shows the room of accumulators of electric pallet trucks and manner of their distribution in the transhipment terminal of a logistics company. According to the guidelines and regulations of work, electric forklift can be used only by those employees who currently are forced to carry bulky goods or goods whose total weight exceeds $450 \mathrm{~kg}$.

Such a change seemed reasonable sonly the appointed workers could enter into the room of accumulators to connect the truck to recharge. Placing of all electric pallets in one room allowed an easy analysis of the state of charge after each shift.

\section{Diagnosis of the problem in the use of electric pallet trucks}

Changes made in the transshipment terminal of the logistics company helped to improve the safety and quality and productivity at work during the transport of goods. Safety audit carried out after one year showed some inconsistencies in the way electric pallet trucks are used by terminal staff and drivers. The failure to comply with work regulations and safety policy was at once with to-day. Employees overused electric pallet trucks, which resulted in an employee carrying an empty pallet.

The cause of the problem should be sought in the high turnover of staff and transferring some of the tasks to external companies, in which the policies of the terminal and safety policy were not implemented. According to employees of external companies, these rules do not apply to them, and the activities taken by them are consistent with the principles of safety and agreed to with their employer. Communication chaos between employees from external companies and employees of the terminal caused the situations in which a worker was using electric pallet truck full shift or until battery depletion. These actions resulted in not placing the electric pallet in a storage place to charge. Consequently, people responsible for loading the trucks needed to look after them throughout the terminal. It is worth noticing that there were also the situations in which trucks were not charged for another shift.

The inclusion of employees of external companies to use electric pallet trucks without adequate training and instructions was the wrong action. Irregularities resulted in a re-examination of the state of safety, which showed that the original problem of transporting goods weighing more than $450 \mathrm{~kg}$ hand pallet truck returned.

\section{Improvement of the use of electric pallet trucks at the terminal}

An audit of the safety team, who initiated the improvement of the transshipment terminal of the logistics company led to the relocation of the electric pallet trucks. According to the auditors, the current changes will not be applicable when trucks are used either by casual workers or employees from external companies. High staff turnover results in the lack of cooperation among employees while loading and unloading goods. Therefore, a team of experts suggested that the employees should control one another. Self-control carried out on the loading ramps will improve the efficiency and quality of the use of electric pallet trucks.

The proposed changes concerned the berth of electric pallet which were moved from the place near accumulators on the area between ramps reloading. Assigning of a specific electric pallet truck to various loading ramps made employees of the terminal, and employees from external companies control each other while using these trucks. The measures taken by the auditors contributed to:

- greater self-control of staff in the use of electric pallet trucks,

- greater self-control of charge condition of electric pallet trucks,

- reduction of the overuse of eclectic trucks to transport goods below $450 \mathrm{~kg}$ or empty pallets,

- co-operation between the employees working at the adjacent loading ramps.

The modification introduced by the team of experts is presented in Figure 1. The comparison of the state after the first change shows that, clearly, it was not applicable in the case of organizational changes at the transhipment terminal of the logistics company (UlewicZ R., MAZUR M., 2015, UlewicZ R., CiUK W. 2006, Ulewicz R., NOWICKA-SKOWRON M. 2016, KADŁUBEK M. INGALDI M., 2016). 


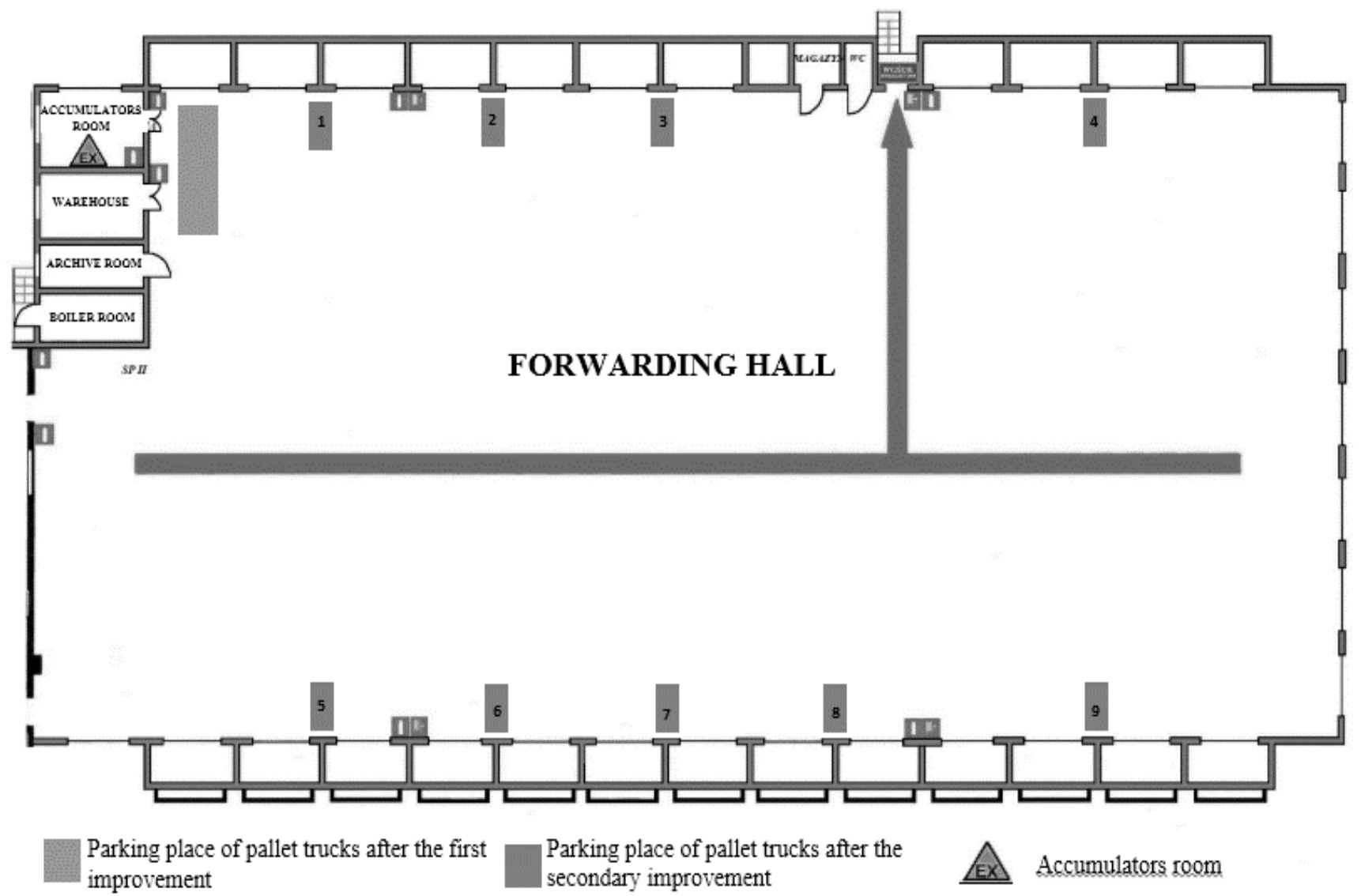

Fig. 1. Location of accumulators and electric pallet trucks after the primary and secondary improvement.

Source: Own study

\section{Conclusions}

Actions taken at the transshipment terminal logistics company confirmed that the process of improvement was a continuous process. The organizational changes in the terminal area (by the introduction of external companies) were carried out improperly, since they were not included in the labor and safety policy. The role of the employer and the safety inspector is cooperation with all employees in the company. The actions carried out by a team of experts enabled greater involvement of workers in the process of inspecting the safety and health at work.

\section{References}

1. Regulation of the Minister of Labor and Social Policy of 26 September 1997 on general safety and health at work (Journal of Law of 2003, No. 169, item. 1650, as amended.)

2. Dobosz M., SAJa P., Pacana A., WoźNy A., Improvement of health and safety conditions at se lected workplaces - on the example of transshipment terminal of a logistics company, [in:] Production Management and Engineering Sciences, London 2016, pp. 55-59. ISBN: 978-1-138-02856-2.

3. UlEwICZ R., MAZUR M., Doskonalenie transportu wewnętrznego z wykorzystaniem koncepcji LEAN - studium przypadku, [in:] Przegląd organizacji, no. 7, Częstochowa 2015.

4. UlewicZ R., CiUK W., The Estimation of Logistic Processes Efficiency in Forwarding Company, EDIS - University of Zilina, Żilina 2006.

5. UlEWICZ R., NOWICKA-SKOWRON M., Lean Tools Influence on the Logistic Process in Production Company, Carpathian Logistics Congress 2016 (CLC 2016), Zakopane, Polska 2016.

6. KADŁUBEK M. INGALDI M., Estimation of the Level of Logistics Customer Service in Enterprise's Management, Carpathian Logistics Congress 2016 (CLC 2016), Zakopane, Polska 2016. 